\title{
The Effect of Ground Granulated Blast Furnace Slag as an Alternative Cement Replacement Material in Concrete after 28 Days Strength - A Review
}

\author{
Amani Sahu ${ }^{1}$, Anisha Mire ${ }^{2}, K_{\text {Divya Kotecha }}{ }^{3}$,Dr. Lokesh singh ${ }^{4}$ \\ ${ }^{I}$ Student of M.tech Structural Engg. ${ }^{2,3}$ Asst.Prof. ,,Dept of Civil Engg. RSR-RCET,Bhilai. \\ ${ }^{4}$ Head of Civil Dept RSR-RCET,Bhilai
}

DOI: 10.46335/IJIES.2020.5.7.9

\begin{abstract}
In the present study an investigation is made on properties of concrete by partial replacement of cement with Ground Granulated Blast furnace Slag $(G G B S)$. GGBS is the by-product of iron and steel industry which is produced in large quantities as a solid waste. It is highly cementitious. The replacement percentages of cement with GGBS are 20\%, 40\% and $60 \%$ by weight.

And it is mentioned that replacement of 40\%-50\% with GGBS gives the best result in compressive strength after 28 days. But it can further be optimized with the very sharp and approximate \% of GGBS.

GGBS is replaced by $40 \%, 42 \%, 44 \%, 46 \%, 48 \%, 50 \%$ by weight of cement and then characteristics compressive strength after 28 days is analyzed and then it is compared with conventional normal concrete strength.
\end{abstract}

Keywords- GGBS, Concrete, Compressive strength.

\section{INTRODUCTION}

C oncrete is the most important material used for construction all over the World. The components of concrete are cement, fine aggregate, coarse aggregate and water. Cement acts as a binding material for concrete. During the production of cement, $\mathrm{CO} 2$ emissions are more in the environment. Many researchers have worked out on the ways of reducing the cement content to avoid the $\mathrm{CO} 2$ emissions. Various byproducts like Fly ash, Silica fume, Metakolin, GGBS can be used as replacement of cement. Due to high price of Natural Sand we have to choose alternative material for it. Quarry dust is the better choice for replacement of sand. Therefore in this study, we have chosen GGBS as replacement of cement. GGBS is obtained by burning molten Iron slag from a blast furnace in water or steam to produce a glassy, granular product which is dried and grounded into a fine powder. GGBS concrete is majorly used in so many construction projects. In New York, construction of the World Trade Centre has about $40 \%$ GGBS as replacement of cement in the concrete (Slag Cement Association, 2005). Minneapolis Airport, the construction of airfield pavements are using 35\% GGBS replacement in the concrete.

\section{II- PROPERTIES OF GGBS}

Ground Granulated Blast furnace Slag (GGBS) GGBS is obtained from local available industries. It is obtained by burning molten Iron slag from a blast furnace in water or steam to produce a glassy, granular product which is dried and grounded into a fine powder. The ground 
granulated blast furnace slag (GGBFS) is a by-product of iron manufacturing which when added to concrete improves its properties such as workability, strength and durability. This material is obtained by the heating of iron ore, limestone and coke at a temperature about 1500 degree Celsius. The process is carried out in a blast furnace. The formation of GGBFS is not direct. The byproduct of iron manufacturing is a molten slag and molten iron. The molten slag consists of alumina and silica, also with the certain amount of oxides. This slag is later granulated by cooling it. For this, it is allowed to pass through a high-pressure water get. This result in quenching of the particles which results in granules of size lesser than $5 \mathrm{~mm}$ in diameter. The main constituents of blast furnace slag are $\mathrm{CaO}, \mathrm{SiO} 2, \mathrm{Al} 2 \mathrm{O} 3$ and $\mathrm{MgO}$. These are the minerals that are found in most of the cementitious substances. The particles are further dried and ground in a rotating ball mill to form a fine powder, known as ground granulated blast furnace slag cement. Now different methods can be employed to perform the main process called as the quenching. Based on what method is employed, it can be known as palletized slag, foamed or expanded slag, GGBFS or air-cooled blast furnace slag (ACBFS).

\section{Composition of Ground Granulated Blast Furnace Slag (GGBFS)}

The difference in mineralogical composition in GGBFS compared to Portland cement is shown in the table below.

\begin{tabular}{|l|l|l|}
\hline Mineral & GGBFS & Portland Cement \\
\hline $\mathrm{CaO}$ & $30-50 \%$ & $55-66 \%$ \\
\hline $\mathrm{SiO} 2$ & $28-40 \%$ & $20-24 \%$ \\
\hline $\mathrm{A} 12 \mathrm{O} 3$ & $8-24 \%$ & $0-8 \%$ \\
\hline $\mathrm{MgO}$ & $1-18 \%$ & $5 \%$ \\
\hline
\end{tabular}

Another significant difference in GGBFS is that some of the metals within it have not undergone complete oxidation. This change will be reflected in the structural formation in concrete when compared with Portland cement.

Advantages Ground Granulated Blast Furnace Slag (GGBFS)
- GGBFS in concrete increases the strength and durability of the concrete structure.

- It reduces voids in concrete hence reducing permeability

- GGBFS gives a workable mix.

- It possesses good pumpable and compaction characteristics

- The structure made of GGBFS constituents help in increasing sulphate attack resistance.

- The penetration of chloride can be decreased.

- The heat of hydration is less compared to conventional mix hydration.

- The alkali-silica reaction is resisted highly.

- These make the concrete more chemically stable

- Gives good surface finish and improves aesthetics

- The color is more even and light.

- Lower chances of efflorescence

- The maintenance and repair cost of structures are reduced thus increasing the life cycle of concrete structures.

- Unlike cement, GGBFS does not produce carbon dioxide, sulphur dioxide or nitrogen oxides.

\section{III- LITERATURE REVIEW}

(a) S.k.Sirajuddin, T.Venkat Das In the present study an investigation is made on properties of concrete by partial replacement of cement with Ground Granulated Blast furnace Slag (GGBS) and the fine aggregate with Quarry Dust (QD). GGBS is the by-product of iron and steel industry which is produced in large quantities as a solid waste. It is highly cementitious. Quarry Dust is a byproduct of the crushing process which is a concentrated material to use especially as fine aggregates. The replacement percentages of cement with GGBS are $20 \%, 40 \%$ and $60 \%$ by weight and fine aggregate with QD are $25 \%, 50 \%$ and $75 \%$ by weight. These combinations of materials were used to study compressive strength, spilt tensile strength and flexural strength tests and the results obtained were compared with the control concrete. It is observed that the optimum replacement percentages of GGBS and QD are $40 \%$ and $50 \%$ respectively.

(b) Gidion Turu'allo Ground granulated blast furnace slag (ggbs) is a waste material generated from iron production, and is one of the cementitious materials that can be used to replace part of the cement in concrete. The aim of this research was to determine the effects of 


\section{Impact Factor Value 5.856 \\ e-ISSN: $2456-3463$ \\ International Journal of Innovations in Engineering and Science, Vol 5, No.7, 2020 \\ $w w w . i j i e s . n e t$}

the water-binder ratios and levels of ggbs in concrete, with regard to the activation energy, which is needed for predicting the concrete's strength. A number of mixtures with different water-binder ratios (ranging from 0.30 to $0.51)$, ggbs levels, and curing temperatures were cast and tested at $0.5,1,2,4,8,16$, and 32 days. The activation energies were determined using the American society for testing and materials (ASTM) standard C1074, and the Freiesleben Hansen and Pedersen (FHP) method. The results of the experiment showed that the apparent activation energy was relatively independent of the water-binder ratio, and mainly affected by the ggbs level in the concrete. Higher ggbs levels in the concrete resulted in the higher apparent activation energies.

(c) Sheikibrahim k, Sathish $\mathbf{S}$ Now a days more cementitious waste materials are produced by the many industries like iron industries (GGBS), coal industries (FLY ASH), paper industries (PAPER ASH) etc. Cement is the most important material in the construction sector. But the cement production from the industries affectsthe environment, due to emission of $\mathrm{CO} 2$ and greenhouse effect. This paper mainly focus on the strength of the concrete by determining the compressive strength and tensile strength of the concrete by various replacement of Flyash and GGBS. The test results shows that strength increasing with the increase offlyash andGGBS up to optimum value beyond which strength value start decreasing with further addition of flyash and GGBS.

(d) Manjit Kaur , Mr. Sanjeev Naval The Ground granulated Blast furnace slag (GGBFS) is a waste of industrial materials, it is relatively more recent pozzolanic material that has received considerable attention in both research and application. It is a nonmetallic product consisting essentially of Silicates and Aluminosilicates of calcium's developed simultaneously with iron in a blast furnace and is granulated by quenching the molten material in water or steam, and air. The present Investigation has been undertaken to study the effect of Ground granulated blast furnace slag and saw dust on the mechanical properties of concrete, when coarse aggregates is replaced by Ground granulated blast furnace slag and saw dust is replaced in different percentages i.e. $0 \%, 5 \%, 10 \%, 15 \%, 20 \%$, and $25 \%$ with the Fine aggregates(sand). The main parameters investigated were cube compressive strength and weight of concrete. The tests were conducted on concrete with ratio $1: 1.5: 3$. The test results indicate that with the use of blast furnace slag by fully replacing coarse aggregates and partially replacing saw dust by fine aggregates in different percentages i.e. $0 \%, 5 \%, 10 \%, 15 \%, 20 \%$, and $25 \%$, the weight of concrete decreases with the increase in the percentage of saw dust. The compressive strength decrease with the increase in percentage of saw dust. The reduction percentage in the compressive strength is $27.14 \%, 44.16 \%, 50.46 \%, 64 \%, 76.53 \%, 80.60 \%$
Replacement of sand by saw dust reduce the unit weight of concrete and make it light weight. The cost of concrete also decreases with the increase in percentage of saw dust. Test result show that, the concrete become lighter than conventional concrete and reducing the environmental hazard and making the concrete economical.

(e) Supriya V K India has an enormous growth in the industry of steel and copper. These industries produce hazardous by products like ground granulated blast furnace slag (GGBS). If they were not disposed off properly, they may cause hazards to the atmosphere. Considering the long term performance and stability of structures, this study suggests replacing some percentage of cement with GGBS to develop high performance concrete. This paper presents an experimental investigation to know the use of GGBS in concrete as a replacing agent of cement.. To accomplish this 53 grade Ordinary Portland cement were used in preparing concrete mix with a w/c ratio of 0.40 with suitable superplasticizers. In order to confirm the use of GGBS as a replacing agent tests were conducted. Cement was replaced with $0 \%$ to $40 \%$ with GGBS respectively. Concrete control specimens without replacement were also cast for comparison. After casting the cube moulds specimens were tested for various tests like compressive strength test, tensile strength test, flexural strength test.

\section{IV- CONCLUSION OF LITERATURE REVIEW}

Most of the researchers had focused on the optimum \% of GGBS for concrete but the area of economy with a proper optimum \% of GGBS is missing, So that it can give strength as conventional concrete and also it remains economical. The area of this field can again be optimized for the sharp and accurate \% replacement of GGBS.

\section{V- CONCLUSION}

(1) From the test results, an increment of $10 \%, 12 \%$ and $15 \%$ observed in Compressive strength, Spilt tensile strength and Flexural strength obtained at 40\% GGBS and 50\% QD replacements of cement and fine aggregate respectively. Finally, we conclude that replacement of cement with $40 \%$ GGBS and fine aggregate with 50\% QD is suitable for getting higher strengths compared with control mix.

(2) The compressive strength GGBS concrete almost more than the FA concrete. This may be due to the fact that GGBS is having high strength when compared with FA. The cost of concrete was reduced by using partial replacement low cost mineral admixtures like FA and GGBS in cement. 
(3) The GGBS and FlyAsh has fully replaced by the cement in concrete for reducing the carbon dioxide emission in the atmosphere. The M40 grade of concrete has attain the compressive strength of $32 \mathrm{Mpa}$ in 28 days and tensile strength of $2.5 \mathrm{Mpa}$ in 28 days. This strength ofGGBS and Fly ash in concrete without adding admixtures. To improve the compressive strength by adding admixtures with GGBS and Fly Ash may gives more strength.

(4) GGBFS Concrete becomes light weight by partially replacing sand with saw dust

(5) The concrete made by using slag as coarse aggregates and partially replacing sand with saw dust used for lean mixes .

(6) GGBFS Concrete can be effectively used by replacing sand up to $15 \%$ with saw dust.

(7) The cost of concrete is less than conventional concrete.

(8) The concrete becomes environment friendly, due to use of waste industrial material.

(9) $20 \%$ replacement of GGBS with cement decreases compressive strength of M40 concrete by $10.8 \%$ \& $40 \%$ replacement decreases compressive strength by $15.4 \%$.

(10) $30 \%$ replacement of GGBS with cement decreases compressive strength of concrete by $1.6 \%$ which is optimum.

(11) Split tensile strength reduces by $19.6 \%$ for $20 \%$ replacement of GGBS with cement \& it reduces by $26.27 \%$ for $40 \%$ replacement of GGBS with cement.

(12) Split tensile strength reduces by $2.6 \%$ for $30 \%$ replacement of GGBS with cement which is found to optimum.

(13) Flexural Strength reduces by $14.19 \%$ for $20 \%$ replacement of GGBS with cement \& it reduces by $21.91 \%$ for $40 \%$ replacement of GGBS with cement.

(14) Flexural Strength reduces by $4.93 \%$ for $30 \%$ replacement of GGBS with cement which is found to optimum.

\section{REFERENCES}

[1] The Effect of Ground Granulated Blast Furnace Slag as an alternative cement replacement material in Concrete after 28 days Strength

[2] https://theconstructor.org/concrete/ggbfs-concreteadvantages/15274/

[3] https://www.irjet.net/archives/V5/i4/IRJET-V5I452.pdf

[4]Dte/Downloads/Usingggbsforpartialcementreplacementinco ncreteeffectsofwater-inderratioandggbslev elonactivationenergyturuallo.Pdf

[5] D.V. Prasada Rao and C.S. Mallikarjuna, "An Experimental investigation of concrete by partial replacement of cement with GGBS and fine aggregate with $Q D, " 2017$.

[6] Oner, A., Akyuz, S. and Yildiz, R. “An experimental study on strength development of concrete containing fly ash and optimum usage of fly ash in concrete", Cement and Concrete Research, Vol. 35, Issue 6, 2005, pp.11651171 .

[7] Shariq, M., Prasad, J., and Ahuja, A.K. "Strength Development of Cement and Concrete Incorporating with GGBS", 2007.

[8] Leung, P.W. and Wong, H.D. "Final Report on durability and strength development of ground granulated blast furnace slag concrete", 2010.

[9] Brooks, J. J., \& Al-Kaisi, A. F, "Early strength development of Portland and slag cement concretes cured at elevated temperatures", Materials Journal, Vol. 87, Issue 5, 1990, pp. 503-507.

[10] Haque, M. N., \& Chulilung, T. "Strength development of slag and ternary blend concrete,". Cement and Concrete Research, Vol. 20, Issue 1, 1990, pp.120-130.

[11] Swamy, R. N., \& Bouikni, A. "Some engineering properties of slag concrete as influenced by mix proportioning and curing," Materials $\backslash$ Journal, Vol. 87, Issue 3, 1990, pp. 210- 220.

[12] Jianyong, Li, and Tian Pei. "Effect of slag and silica fume on mechanical properties of high strength concrete," Cement and Concrete Research, Vol. 27, Issue 6, 1997, pp. 833-837. 